\title{
Süzme ve petekli balların pestisit, naftalin ve antibiyotik kalıntıları bakımından karşılaştırılması
}

\section{Comparison of liquid and comb honeys for pesticide, naphthalene and antibiotic residues}

\author{
Erkan ÇAKAR ${ }^{1}$, Fehmi GÜREL ${ }^{2}$ (D) \\ 1İbradı İlçe Tarım ve Orman Müdürlüğü, İbradı, Antalya \\ ${ }^{2}$ Akdeniz Üniversitesi, Ziraat Fakültesi, Zootekni Bölümü, Antalya \\ Sorumlu yazar (Corresponding author): F. Gürel, e-posta (e-mail): fgurel@akdeniz.edu.tr \\ Yazar(lar) e-posta (Author e-mail): erkancakar@live.fr
}

\section{MAKALE BİLGİSI}

Alınış tarihi 16 Temmuz 2019

Düzeltilme tarihi 20 Ağustos 2019

Kabul tarihi 20 Ağustos 2019

\section{Anahtar Kelimeler:}

Bal

Kalıntı

Antibiyotik

Naftalin

Pestisit

\section{ÖZ}

Bu çalışmada bal örnekleri içerisindeki pestisit, naftalin ve antibiyotik kalıntılarını belirlemek ve süzme ve petekli bal örneklerini kalıntı içeriği bakımından karşılaştırmak amaçlanmıştır Antalya ili Akseki ve İbradı ilçelerinde arı yetiştiricilerinden alınan toplam 60 adet bal örneğinde 330 adet pestisit bileşeni, 25 adet antibiyotik bileșeni ve naftalin kalıntı analizi sıvı kromatografi tandem kütle spektrometre (LC-MS/MS) ve gaz kromatografi kütle spektrometre (GC-MS) cihazları kullanılarak yapılmıştır. Her bir arıcıdan bir adedi eski bir adedi yeni olmak üzere toplam 30 dolu çerçeve petekli bal alınmış ve her çerçeve petekli bal ikiye ayrılarak yarısı süzülmüş, yarısı da petekli olarak etiketlenmiş ve analiz edilmiştir. Analiz sonucunda, incelenen 330 adet pestisit ve 25 adet antibiyotik bileșeni kalıntısı hiçbir örnekte bulunmamıştır. Yalnız üç adet petekli bal örneğinde 3.0, 3.9 ve $8.9 \mu \mathrm{g} \mathrm{kg}^{-1}$ düzeyinde naftalin kalıntısı tespit edilmiştir. Ancak bu üç örnekte de naftalin kalıntı düzeyi, Türk Gıda Kodeksi Bal Tebliğinde naftalin için belirtilen $10 \mu \mathrm{g} \mathrm{kg}^{-1}$ düzeyinin altındadır. Naftalin içeren üç çerçeve petekli balın yarısından alınan süzme bal örneklerinde, naftalin kalıntısına rastlanmaması petekli balların süzme ballara göre naftalin kalıntısı bakımından daha fazla risk taşıdığını göstermektedir. Sonuç olarak, ülkemiz ballarındaki kalıntı sorununun çözümüne arıcıların eğitimi, hızlı ve ucuz kalıntı analiz ve izleme tekniklerinin geliştirilmesi gibi bazı uygulamaların önemli katkı sağladığı anlaşılmaktadır.

\section{ARTICLE INFO}

Received 16 July 2019

Received in revised form 20 August 2019 Accepted 20 August 2019

\section{Keywords:}

Honey

Residue

Antibiotic

Naphthalene

Pesticide

\begin{abstract}
This study was aimed to determine pesticide, naphthalene and antibiotic residues in honey and to compare these residues in liquid and comb honeys. A total of 60 honey samples were collected by beekeepers in Antalya (Akseki-Ibrad1) and analyzed for 330 pesticide compounds, 25 antibiotic compounds and naphthalene residues using liquid chromatography tandem mass spectrometry (LC-MS/MS) and gas chromatography mass spectrometry (GC-MS). Two full frames of comb honey (old, dark and fresh, white) were obtained by same beekeepers directly from the colony. Each full frame of comb honey was divided into two portions to compare residue content between comb honeys and liquid honeys. The first portion of honeycomb was extracted and the second one retained original form. Residues of 330 pesticide compounds, and 25 antibiotic compounds were not detected in the analyzed honey samples. Only three comb honey samples were contaminated with naphthalene at $3.0 \mu \mathrm{g} \mathrm{kg}^{-1}, 3.9 \mu \mathrm{g} \mathrm{kg}^{-1}$, and 8.9 $\mu \mathrm{g} \mathrm{kg}^{-1}$. However, these naphthalene residues detected were below the maximum residue limit $\left(10 \mu \mathrm{g} \mathrm{kg}^{-1}\right)$ prescribed in the Turkish Honey Codex. The absence of naphthalene residues in the liquid honey samples derived from these three contaminated comb honey samples shows that comb honeys carry a higher risk of naphthalene residue than the liquid honeys. In conclusion, some practices such as the training of beekeepers, development of relatively quick and inexpensive residue analyze techniques and strict residue monitoring systems have been effective to prevent residues in Turkish honeys.
\end{abstract}




\section{Giriş}

Tarımsal üretimde verimi artırmak amacıyla özellikle son çeyrek yüzyılda geliştirilen teknik ve uygulamalar hem bitkisel üretimde hem de bal arısı yetiştiriciliğinde kimyasal madde kullanımını artırmıştır. Bu nedenle, günümüzde bal arıları daha yoğun bir şekilde kimyasal maddelerin olumsuz etkilerine maruz kalmaktadır. Bal arısı kolonileri çok sayıda iç ve dış parazitler, protozoa, virüs, bakteri gibi hastalı yapan organizmalar (patojenler) tarafindan etkilenmekte ve bu patojenlerle mücadele edilmediği zaman, bal ve diğer arı ürünleri üretiminde büyük kayıplar yaşanmaktadır. Bu nedenle hem dünyada hem de ülkemizde bal arısı hastalık ve zararlılarıyla mücadele amacıyla kimyasal ilaçlar yoğun olarak kullanılmaya başlanmıştır. Ancak kimyasal ilaçların kullanılmasıyla bir taraftan kullanılan ilaçlara karşı direnç gelişmiş ve ilaçların etkinliği azalmış diğer taraftan bal ve arı ürünlerinde oluşan ilaç kalıntıları insan sağlığı açısından büyük sorun yaratmıştır. Türkiye' de ruhsatlı ilaçların yanı sıra ruhsatsız çok sayıda ilaç kontrolsüz bir şekilde kullanılmaktadır. Hastalıklara karşı mücadelede ruhsatlı ilaçların kullanılmasında bile çok uzun süreli uygulama, doz aşımı, nektar akımı döneminde uygulama gibi işlemler sonucunda insanların tüketimine sunulan balda istenmeyen bulaşmalar olmaktadır. Ayrıca ihbarı mecbur ve en tehlikeli bakteriyel hastalıklardan birisi olan Amerikan Yavru Çürüklügü Hastalığı ile mücadele sırasında bazı arıcılar yasak olmasına rağmen antibiyotik kullanmakta, kullanılan bu antibiyotikler balda ve petekte kalıntı bırakmakta ve insan sağlığını tehdit etmektedir. Bu nedenle son yıllarda uluslararası bal ticaretinde en çok dikkat edilen ve incelenen özelliklerden birisi de balda antibiyotik kalıntısıdır. Antibiyotik kullanımının kesinlikle yasak olması ve bu konuda cezai yaptırımlar olmasına karşın, zaman zaman ballarda antibiyotik kalıntısı çıkmaktadır (Derebașı ve ark. 2014; Sayg111 2017).

Balda kalıntının diğer bir kaynağı da boş petekleri korumak için kullanılan naftalindir. Sonbaharda petekli ballar süzüldükten sonra uygun olmayan koşullarda muhafaza edilen kabartılmış boş peteklere mum güvesi önemli zararlar vermektedir. Boş petekleri korumak için naftalin uygulaması geçmiş yıllarda yaygın bir şekilde kullanılmıştır. Naftalin çok tehlikeli kanserojen bir maddedir ve bal mumu tarafindan emilip uzun süre muhafaza edilmektedir. Boş petekler yeniden koloniye verildiğinde içerdikleri naftalin bala geçmektedir. Ayrıca eritilen eski peteklerdeki naftalin kalıntıları da yeni muma ve temel peteklere geçmektedir. $\mathrm{Bu}$ nedenlerle arıcılıkta naftalin kullanımı yasaklanmıştır. Kabartılmış petekleri mum güvesinden korumak için petekleri soğuk hava depolarında muhafaza etmek gibi zararsız yöntemler bulunmasına rağmen zaman zaman az da olsa naftalin kalıntılı ballara rastlanmaktadır (Tutkun ve İnci 1992; Gürel 2012). Ülkemiz bal tüketicileri için ilave bir risk de Türkiye'ye özgü olarak petekli bal tüketiminin diğer ülkelere oranla oldukça yaygın olmasıdır. Petekli bal satışı bazı ülkelerde yasaklanmıştır ve birçok ülkede de yaygın olarak süzme bal tüketilmektedir. Türkiye bal mumu üretim miktarı y1llara göre (2005-2017) değişmekle birlikte 4000-4500 ton arasındadır. Son 10 yıl içinde bal üretiminde yaklaşık \%25 artış sağlanmıştır (Anonim 2018). Petekli bal üretiminin ve arılı kovan sayısının da sürekli arttığı düşünüldüğünde bal mumuna olan talep de sürekli artmaktadır. Bu nedenle Türkiye büyük miktarda bal mumu ithal etmektedir. Sanayi ürünü olarak ithalatı yapılan ve kontrol edilmeyen balmumlarında bazı kalıntılar ve hastalık etmenleri de bulunabilmektedir.
Kültür bitkileri yetiştiriciliğinde hastalık ve zararlılara karşı kullanılan kimyasallar dolaylı olarak bal arısı kolonilerini etkilemektedir. Tarımsal mücadele amacıyla kimyasal ilaç kullanımının; insana, doğal çevreye ve gıda güvenliğine olası olumsuz etkilerini en aza indirecek şekilde kontrollü, uygun dozlarda ve bitkinin fenolojisine uygun şekilde yapılmas1 gerekmektedir. Ülkemiz bal arısı yetiştiriciliğinde, sıklıkla tarım ilaçlarının olumsuz etkileri yaşanmakta ve zaman zaman kimyasal ilaçlamalardan kaynaklı çok miktarda arı ölümleri görülmektedir. Ayrıca bu kimyasallar bal arılarının besin kaynakları olan nektar ve polene bulaşmakta ve kovana taşınarak arı ürünlerinde kalıntıya yol açmaktadır.

Son y1llarda, uluslararası bal ticaretinde de en önemli konuyu kalıntı içeren ballar oluşturmaktadır. En fazla bal ihracatı yapan ülke olan Çin' in bal ihracatına da kalıntı içeriğinden dolayı sınırlamalar getirilmektedir. $\mathrm{Bu}$ nedenle son yıllarda bal arısı ürünlerinde kalıntı belirlenmesine yönelik araştırmalar artmıştır. Kalıntı analiz tekniklerindeki gelişmeler de daha güvenilir ve hızlı sonuçların elde edilmesini sağlamıştır. Türkiye'nin y1llık bal üretimi yüz bin ton'un üzerindedir. Türkiye'nin yıllık bal ihracatı yıllara göre, toplam bal üretiminin \%1-5 arasında değişim göstermektedir (Anonim 2018). Dünyada koloni sayısı bakımından 2. sırada bulunan ülkemiz ihracatta çok gerilerde yer almaktadır. Antibiyotik, pestisit, naftalin kalıntıları geçmiş yıllardaki bal ihracatımızda önemli sorunlar yaratmıştır. Bu nedenle hem iç tüketim hem de dış satım için güncel analiz teknikleri ile balda kalıntı durumunun araştırılması ve kalıntı sorununun çözümüne katkı sağlayacak önlemlerin alınması gerekmektedir.

Ülkemizdeki ballarda kalıntı miktarının azaltılması için yoğun çaba sarf edilmektedir. Antibiyotik ve naftalin kullanımı yasaklanmıştır. Ülkemizde, Avrupa Birliği uyum yasaları çerçevesinde üreticilerin örgütlenmesi ve kayıt altına alınabilmesi amacıyla arı yetiştiricileri birlikleri ve merkez birliği kurulmuş, üretilen ürünlerin bütün süreçlerde denetlenebilmesi için de $\mathrm{ABD}$ ve Avrupa Birliği ülkelerindekine benzer şekilde hazırlanan bal tebliğ ve bal eylem planı uygulamaya konulmuştur (Anonim 2012). Bal tebliğinde; temel petek, bal mumu ve balın tanımı ve içeriği, balın naftalin, antibiyotik, ticari glikoz ve nişasta içermeyeceği, bala hiçbir katkı maddesi katılamayacağı, balda bulunabilecek maksimum pestisit kalıntı miktarları ve baldaki veteriner ilaçları tolerans düzeyleri, balın ambalajlanması, etiketlenmesi, taşınması, depolanması ve tescil ve denetimine ilişkin hükümler açık olarak belirtilmiştir. Bütün bu gelişmelere karşı ülkemiz arıcılık sektörü, verimlilik ve uluslararası standartlarda üretim konusundaki sorunlarını henüz çözememiştir. Son yıllarda yaygın bir şekilde görülen çeşitli yöntemlerle doğal yapısına müdahale edilmiş (tağşiş edilmiş) ballar ve kalıntı içeren bal üretimi hem iç piyasada hem de ihracatta önemli sorunlara yol açmaktadır. Ayrıca tüketiciler bütün ballara şüphe ile bakmakta ve bu yüzden balın saf, doğal imajı bozulmaktadır. İnsan sağlığının korunması amacıyla Türk Gıda Kodeksi'nde verilen limitlerin üzerinde bulunan veya izinsiz kullanılan veteriner ilaçları balda gıda güvenliğini tehlikeye atmaktadır. Yasal mevzuatın uygulanması büyük ölçüde mesleki örgütlenme ve mesleğin etik ilkelerinin çok iyi kavranması ile olacaktır. Etkin denetim sistemi ve bilimsel çalışmalar sorunun çözümüne katk1 sağlayacaktır (Gürel 2012, 2015).

$\mathrm{Bu}$ çalışmada süzme ve petekli bal örneklerini pestisit, antibiyotik ve naftalin kalıntı içeriği bakımından karşılaştırmak amacıyla; Antalya ili Akseki ve İbradı ilçelerinde Arı Yetiştiricileri Birliği'ne kayıtlı en az 30 kovana sahip ticari 
olarak bal üretimi yapan 15 arıcıdan bir adedi eski bir adedi yeni olmak üzere toplam 30 dolu çerçeve petekli bal alınmış ve her çerçeve petekli bal ikiye ayrılarak yarısı süzülmüş, yarısı da petekli olarak etiketlenmiş ve analiz edilmiştir. Petek doğal yapısından dolayı pestisit, antibiyotik ve naftalin kalıntılarını emen ve depolayan bir üründür. $\mathrm{Bu}$ nedenle petekli ballarda kalıntı içeriğinin daha fazla olması beklenir. Benzer şekilde koyu renkli petekler kovanda daha uzun süre kaldığı için açık renkli (yeni) peteklere oranla daha fazla kalıntı riski taşımaktadır. Ancak yapılan kaynak taramasında süzme ve petekli balların pestisit, antibiyotik ve naftalin kalıntıları bakımından karşılaştırılması ve petekli ballarda da koyu (eski) ve açık renkli (yeni) petekli ballarda kalıntı miktarının durumu konusunda çalışmaya rastlanmamıştır. Sonuç olarak, çalışma ile bu konudaki bilimsel veri eksikliğinin giderilmesi ve tüketici bilincinin artırılmasına katkı sağlanması hedeflenmiştir.

\section{Materyal ve Yöntem}

\subsection{Materyal}

Çalışmada Akdeniz Bölgesi'nde bal üretiminin yoğun yapıldığı Akseki ve İbradı ilçelerine ait yaylalardan Ağustos (2017) - Eylül (2017) aylarında Arı Yetiştiricileri Birliği’ne kayitlı en az 30 kovana sahip ticari olarak bal üretimi yapan yöre arıcılardan alınan ballar araştırma materyali olarak kullanılmıştır. Toplam 15 arıcının her birinden peteklerin yarısından fazlasının sırlanmış olmasına dikkat edilerek bir adedi koyu renkli (eski) ve bir adedi açık renkli (yeni) olmak üzere iki çerçeve petekli bal alınmıştır. Laboratuvara getirilen her bir çerçeve petekli bal ikiye ayrılarak yarısı süzülmüş diğer yarısı ise petekli olarak 500 gramlık örnek kaplarına yerleştirilmiştir. Her arıcıya ait koyu renkli petekli bal, koyu renkli peteklerden süzülen süzme bal, açık renkli petekli bal ve açı renkli peteklerden süzülen süzme bal olmak üzere 4 farklı örnek olmak üzere toplam 60 bal örneği etiketlenerek kalıntı analiz laboratuvarına teslim edilene kadar oda koşullarında muhafaza edilmiştir. Bal örneklerinde pestisit, naftalin ve antibiyotik kalıntı analizleri Akdeniz Üniversitesi Gıda Güvenliği ve Tarımsal Araştırmalar Merkezi Laboratuvarlarında yapılmıştır. Merkez kamu ve özel sektöre bal analizleri konusunda hizmet vermekte ve merkezde rutin olarak kalıntı analizleri yapılmaktadır.

\subsection{Metot}

\subsubsection{Bal örneklerinde pestisit analizi}

Pestisit analizleri genel olarak örnek hazırlama aşamas1, ekstraksiyon aşaması (pestisit kalıntılarının örnek yapısından ayrılarak toplanması aşaması), temizleme aşaması (clean-up; extrakt içerisinde kalan analiz sonuçlarını ve cihazı olumsuz etkileyen büyük moleküllü bileşiklerin uzaklaştırılması aşaması) ve analiz aşaması olmak üzere 4 aşamada gerçekleştirilmektedir. Pestisit analizlerinde en yaygın kullanıma sahip olan ektraksiyon metodu "QuEChERS" (Quick, Easy, Cheap, Effective, Rugged, Safe) metodudur. Bu metot farklı yapıdaki yüksek sayıda pestisitin farklı matrikslerde analiz edilmelerine olanak sağlayan hızlı, kolay, ucuz, etkili, sağlam ve güvenli ekstraksiyon metodu olarak tanımlanmıştır (Lehotay ve ark. 2007; Açar 2015). Pestisit analizlerinin yapılabilmesi için süzme ve petekli bal örnekleri ön hazırlık işlemleri yapıldıktan sonra LC-MS/MS cihazında (Modeli: Thermo Scientific Accela UHPLC- TSQ Quantum Access Max, Kolon: Hypersil GOLD RP C18 $(1.9 \mu \mathrm{m}), 50 \times 2.1 \mathrm{~mm})$
QuEChERS yöntemi ile ekstraksiyonu gerçekleştirilmiştir. Ekstraksiyon solventi olarak asetonitril kullanılmış ve yapılan ekstraksiyonun kalitesi internal standart olarak diethatyl ethyl (DEE) kimyasalı kullanılarak kontrol alına alınmıştır. Analizi yapılan 330 adet pestisit bileşenlerinin isimleri Çizelge 1'de verilmiştir.

\subsubsection{Bal örneklerinde antibiyotik analizi}

Bal örneklerinde sülfonamid ve tetrasiklin grubu antibiyotik kalıntı miktarları örneklerin homojenize edilmesi ve örnek hazırlama işlemlerinin tamamlanmasından sonra LC-MS/MS cihazı (Modeli: UHPLC-MS/MS sistem : Thermo Access Max UHPLC - MS/MS Sytems ( ESI ionization), Kolon: $50 \mathrm{~mm}$ uzunluğunda, $2.1 \mathrm{~mm}$ id, $1.9-\mu \mathrm{m}$ particle size C18 UHPLC analitik kolon ve eşdeğeri) kullanılarak belirlenmiştir (Zai ve ark. 2013). Analizi yapılan sulfonamid ve tetrasiklin grubu antibiyotikler ve raporlama limitleri Cizelge 2' de verilmiştir.

\subsubsection{Bal örneklerinde naftalin analizi}

Bal numunelerinde naftalin kalıntısı GC-MSD cihazı (GCMS Thermo Trace GC Ultra ISQ, Autosampler: Triplus Autoinjector Thermo Scientific HP-5MS capillary column (15 $\mathrm{m} \times 0.25 \mathrm{~mm} \times 0.25 \mu \mathrm{m})$ kullanılarak headspace yöntemi ile gerçekleştirilmiştir. Headspace yöntemi ile numunede naftalin kalıntı miktarının tespiti amacıyla, numunedeki naftalinin 1sıtılması yoluyla uçucu hale gelmesi esasına dayanmaktadır (Açar 2015).

\section{Bulgular ve Tartışma}

Çalışmada Sıvı Kromatografi Tandem Kütle Spektrometre (LC-MS/MS) cihazı kullanılarak 30 adet süzme bal ve 30 adet petekli bal örneği olmak üzere toplam 60 adet bal örneğinde toplam 330 adet pestisit bileşeninin ve 20 adet sulfonamid grubu ve 5 adet tetrasiklin grubu olmak üzere toplam 25 adet antibiyotik bileşeninin kalıntı analizi yapılmıştır (Cizelge 1 ve 2). Analizi yapılan bal örneklerinin hiç birinde 330 adet pestisit ve 25 adet antibiyotik bileşeninin kalıntılarına rastlanmamıştır. Balda tespit edilen pestisit kalıntıları genellikle varroa mücadelesinde kullanılan ilaçlardan kaynaklanmaktadır. Bu sonuçlar örnek alınan bölgedeki arıcıların varroa mücadelesinde gerekli özeni gösterdiklerini doğrulamaktadır. Varroa mücadelesinde erken ilkbaharda ve geç sonbaharda ruhsatlı ilaçların önerilen dozda kullanılması balda kalıntı riskini önlemede en öncelikli uygulamadır. Ülkemiz ballarındaki kalıntı tespitine yönelik geçmiş yıllarda yapılan bazı çalışmalarda ise incelenen bal örneklerinde varroa mücadelesinde kullanılan ilaçların etkin maddeleri tepsi edilmiştir. Selçukoğlu (1999) doktora tez çalışmasında Çukurova Bölgesi'nde toplanan 135 bal örneğinde amitraz ve fluvalinate kalıntılarını incelemiş ve hiçbir örnekte fluvalinate kalıntısına rastlamadığını ancak 25 örnekte amitraz kalıntısına rastladığını belirtmiştir. Gül (2008) tarafindan yapılan doktora tez çalışmasında ise Türkiye genelinden 200 arıcıdan alınan 600 adet ve marketlerden toplanan 10 adet bal örneğinde yapilan pestisit kalıntı analizinde ise, Türkiye geneli amitraz kalıntı miktar1 \%4.7, coumaphos kalıntı miktarı ise \%1.4 olarak tespit edilmiştir. Derebaș1 ve ark. (2014) Karadeniz Bölgesi'ndeki 17 ilde bulunan arıcılardan toplanan 209 petekli bal örneğinde yaptıkları pestisit kalıntı analizinde ise amitraz ve flumethrin etken maddelerini sirasıla; $\% 21$ ve $\% 34.9$ oranında ve 57.9 167.4 ppb ve 20.9 - 38.6 ppb aralığında saptamışlardır. 
Çizelge 1. Analizi yapılan pestisit bileşenlerinin listesi.

Table 1. List of the investigated pesticide compounds.

\begin{tabular}{|c|c|c|c|c|c|}
\hline $2,4-\mathrm{D}$ & carbofuran & dichlofluanid & fenvalerate & metsulfuron-methyl & pyrazophos \\
\hline 2,4-DDD & c.-3-hydroxy & d.benzophenone- 4,4 & fipronil & mevinphos & pyridaben \\
\hline 2,4-DDE & carbosulfan & dichlorvos & fluazifop-p-buthyl & molinate & pyridaphenthion \\
\hline 2,4-DDT & carboxin & diclofop-methyl & flucythrinate & monocrotophos & pyridate \\
\hline 2,4-dimethylaniline & chinomethionate & dicofol & fludioxonil & monolinuron & pyrifenox \\
\hline 3,5-dichloroaniline & chlorbenside & dicrotophos & flufenoxuron & myclobutanil & pyrimethanil \\
\hline 4,4-DDD & chlorbromuron & dieldrin & flumioxazine & nitrofen & pyriproxyfen \\
\hline 4,4-DDE & chlordane-cis & diethofencarb & flurochloridone & nitrothal-isopropyl & quinalphos \\
\hline 4,4-DDT & chlordane-trans & difenoconazole & fluroxypyr & nonachlor & quintozene \\
\hline abamectin & chlordecone & diflubenzuron & flusilazole & nuarimol & resmethrin \\
\hline acephate & chlorfenapyr & dimethoate & flutriafol & omethoate & simazine \\
\hline acetachlor & chlorfenson & dimethomorph & fluvalinate_tau & oxadiazon & spinosad-A \\
\hline acetamiprid & chlorfenvinphos & diniconazole & folpet & oxadixyl & spinosad-D \\
\hline acibenzolar-s- & chlorfluazuron & dinitramine & formothion & oxamyl & spiroxamine \\
\hline aclonifen & chloridazon & dinobuton & fosthiazate & oxyfluorfen & sulfosulfuron \\
\hline acrinathrin & chlormequat chloride & dinoseb & furathiocarb & paclobutrazole & $\mathrm{T}-2.4 .5-$ \\
\hline alachlor & chlorobenzilate & dinoseb acetate & $\mathrm{HCH}$ & parathion-ethyl & tebuconazole \\
\hline aldicarb & chlorothalonil & dinoterb & HCH-alpha & parathion-methyl & tebufenozide \\
\hline aldicarb-sulfone & chloroxuron & dioxathion & $\mathrm{HCH}$-beta & penconazole & tebufenpyrad \\
\hline aldicarb-sulfoxide & chlorpropham & diphenamid & $\mathrm{HCH}$-delta & pencycuron & tecnazene \\
\hline aldrin & chlorpyrifos & diphenylamine & $\mathrm{HCH}$-gamma & pendimethalin & teflubenzuron \\
\hline amitraz & chlorpyrifos methyl & disulfoton & heptachlor & pentachlorophenol & tefluthrin \\
\hline amitrole & chlozolinate & ditalimfos & h. endo-epoxide & permethrin-cis & terbufos \\
\hline anilazine & cinidon-ethyl & dithianon & h. exo-epoxide & permethrin-trans & terbuthylazine \\
\hline aramite & clod.-propargyl ester & diuron & heptenophos & phenmedipham & terbutryn \\
\hline atrazine & clofentezine & dodemorph & hexaconazole & phenothrin & tetrachlorvinphos \\
\hline azimsulfuron & cyanazine & endosulfan-alpha & hexaflumuron & phenthoate & tetradifon \\
\hline azinphos-ethyl & cycloate & endosulfan-beta & hexythiazox & phenylphenol-2 & tetramethrin \\
\hline azinphos-methyl & cycloxydim & endosulfan-sulfate & imazalil & phorate & tetrasul \\
\hline azoxystrobin & cyfluthrin,alpha & endrin & imidacloprid & phosalone & thiabendazole \\
\hline barban & cyfluthrin,beta & epoxyconazole & ioxynil & phosmet & thiacloprid \\
\hline benalaxyl & cyfluthrin,teta & esfenvalerate & iprodione & phosphamidon & thiamethoxam \\
\hline bendiocarb & cyfluthrin,zeta & ethalfluralin & iprovalicarb & phoxim & thiazopyr \\
\hline benfuracarb & cyhalofop-butyl & ethiofencarb & isoproturon & picloram & thifensulfuron- \\
\hline benomyl & cyhalothrin-lambda & e.-sulfone & kresoxim-methyl & picolinafen & thiodicarb \\
\hline bentazone & cyhexatin & e.-sulfoxide & lenacil & piperonyl-butoxide & thiometon \\
\hline bifenthrin & cymoxanil & ethion & linuron & pirimicarb & thiophanate-methyl \\
\hline binapacryl & cypermethrin,alpha & ethirimol & lufenuron & pirimiphos-ethyl & tolclofos-methyl \\
\hline bioallethrin & cypermethrin,beta & ethofumesate & malaoxon & pirimiphos-methyl & tolylfluanid \\
\hline bitertanol & cypermethrin,teta & ethoprophos & malathion & prochloraz & triadimefon \\
\hline boscalid & cypermethrin,zeta & etoxazole & mecarbam & procymidone & triadimenol \\
\hline bromacil & cyproconazole & etridiazole & metabromuron & profenofos & triallate \\
\hline bromophos-ethyl & cyprodinil & etrimfos & metalaxyl & prometryn & triasulfuron \\
\hline bromopropylate & cyromazine & famoxadone & metalaxyl-m & propamocarb & triazophos \\
\hline bromoxynil & daminozide & fenamiphos & metamitron & propanil & tribenuron methyl \\
\hline bromuconazole & dazomet & fenarimol & methamidophos & propargite & trichlorfon \\
\hline bupirimate & deltamethrin & fenazaquin & methidathion & propazine & tridemorph \\
\hline buprofezin & demeton $(\mathrm{o}+\mathrm{s})$ & fenbuconazole & methiocarb & propham & trifloxystrobin \\
\hline butocarboxim & demeton-s-methyl & fenchlorphos & m.-sulfone & propiconazole & triflumizole \\
\hline butralin & demeton-s-methyl & fenhexamid & m.sulfoxide & propoxur & trifluralin \\
\hline cadusafos & demeton-s-methyl- & fenithrothion & methomyl & propyzamide & triforine \\
\hline captafol & desmedipham & fenoxycarb & methoxychlor & prosulfuron & tris \\
\hline captan & dialifos & fenpropathrin & metolachlor & prothiophos & vamidothion \\
\hline carbaryl & diallate & fenpropimorph & metoxuron & pymetrozine & vinclozolin \\
\hline carbendazim & diazinon & fenthion & metribuzin & pyraflufen-ethyl & zoxamide \\
\hline
\end{tabular}


Çizelge 2. Analizi yapılan antibiyotikler ve raporlama limitleri.

Table 2. List of the investigated antibiotic compounds.

\begin{tabular}{|c|c|c|c|}
\hline Antibiyotik & Raporlama Limiti $\left(\mathrm{mg} \mathrm{kg}^{-1}\right)$ & Antibiyotik & Raporlama Limiti (mg kg-1) \\
\hline \multicolumn{2}{|c|}{ Sulfonamid grubu } & & \\
\hline sulfanilamide & 0.010 & sulfometer & 0.010 \\
\hline sulfacetamide & 0.010 & sulfamethoxypyridazine & 0.010 \\
\hline sulfacetamide & 0.010 & sulfachloropyridazine & 0.010 \\
\hline sulfapyridine & 0.010 & sulfaquinoxaline & 0.010 \\
\hline sulfadiazine & 0.010 & sufadoxine & 0.010 \\
\hline sulfamethoxazole & 0.010 & sulfadimethoxine & 0.010 \\
\hline sulfathiazole & 0.010 & sulfaphenazole & 0.010 \\
\hline sulfomerazine & 0.010 & Tetrasiklin grubu & \\
\hline sulfisoxazole & 0.010 & methacycline & 0.010 \\
\hline sulfamethizole & 0.010 & doxycycline & 0.010 \\
\hline sulfabenzamide & 0.010 & tetracycline & 0.010 \\
\hline sulfamethazine & 0.010 & oxytetracycline & 0.010 \\
\hline sulfamonomethioxine & 0.010 & chlortetracycline & 0.010 \\
\hline
\end{tabular}

Bal arılarında yavru çürüklüğü hastalıklarına karşı kullanılan antibiyotikler de önemli bir kalıntı kaynağıdır. Avrupa Birliği antibiyotikle tedaviye izin vermemektedir. Antibiyotiklerin kullanımına izin verilmediği için maksimum kalıntı limitleri (MRL) de belirtilmemiştir. Ülkemiz ballarında yapılan çalışmalarda antibiyotik kalıntısına rastlanmış ve özellikle bal ihracatında bu durum önemli bir sorun yaratmıştır. Bu nedenle ülkemizde de antibiyotik kullanımı yasaklanmıștır. Uludağ (2008) tarafindan yapılan yüksek lisans tez çalışmasında Ege Bölgesinden toplanan 103 bal örneğinin \%23'ünde sülfonamid grubu anibiyotik kalıntısı tespit edilmiş; pozitif örneklerin $\% 68$ 'inin sülfametazin, $\% 12$ 'sinin sülfamerazin, ve $\% 20$ 'sinin de sülfametoksazol ile bulaşık olduğu belirlenmiştir. Gül (2008) tarafindan yapılan doktora tez çalışmasında ise Türkiye genelinden 200 arıcıdan alınan 600 adet ve marketlerden toplanan 10 adet bal örneğinde yapılan antibiyotik analizlerinde $\% 29.5$ oranında sülfonamid, \%3.3 oranında tetrasiklin, \%11.9 oranında streptomisin kalıntıları içerdiği belirlenmiștir. Derebașı ve ark. (2014) Karadeniz Bölgesi’ndeki 17 ilde bulunan arıcılardan 2007 yılında topladıkları 209 petekli bal örneğinin 13 adedinde streptomisin 59 adedinde sulphonamid ve 7 adedinde de tetrasiklin tespit etmişler ve bu örneklerin hem uluslararası hem de ulusal bal kodeksine uygun olmadığını belirtmişlerdir. Saygılı (2017) tarafından yapılan yüksek lisans tez çalışmasında ise Kırklareli ili civarında arıcılık yapan 57 üreticiden alınan petek örneklerinde yapılan analiz sonucunda herhangi bir antibiyotik kalıntısı bulunmamıştır. Benzer şekilde bu araştırmada da incelenen bal örneklerinin hiç birinde 20 adet sulfonamid grubu ve 5 adet tetrasiklin grubu olmak üzere oplam 25 adet antibiyotik bileşeninin kalıntısına rastlanmamıştır. Bu nedenle bu çalışmanın sonuçları da son yıllarda antibiyotik kullanımının engellenmesinde önemli kazanımlar sağlandığını göstermektedir.

Mum güvesi (Galleria mellonella L.) bir sonraki y1l kullanılmak üzere saklanan peteklerde önemli hasarlara neden olan bir zararlıdır. Petekleri mum güvesinden korumak amacıyla kullanılan naftalinin zararlı etkilerinin ortaya çıkması sonucunda birçok ülkede naftalin kullanımı yasaklanmıştır. Avrupa Birliği'nde 2005 yılından itibaren naftalin için izin verilen maksimum kalıntı limiti $10 \mu \mathrm{g} \mathrm{kg}^{-1}$ (ppb) olarak belirlenmiştir. Bu limit aynı düzeyde (10 ppb olarak) Türk Gıda Kodeksi Bal Tebliği'nde de yer almaktadır (Anonim 2012). Türk ballarının naftalin içeriği ile ilgili araştırmalara 2000'li yıllarda başlanmıştır. Beyoğlu ve Omurtag (2007) analiz edilen
100 adet bal örneğinin bir tanesinde $1.13 \mu \mathrm{g} \mathrm{kg}^{-1}$ düzeyinde naftalin kalıntısı tespit etmişlerdir. Karacaoğlu ve ark. (2012) tarafindan yapılan çalışmada ise naftalin uygulaması yapılan temel peteklerin 60 gün havalandırması ile kalıntı miktarının önemli düzeyde $(\mathrm{P}<0.05)$ azaldığı belirlenmiştir. Şireli (2013) tarafından yürütülen bir çalışmada ise Türkiye'nin farklı iklim ve coğrafik bölgelerinde üretilen ve Ankara'da tüketime sunulan 120 adet ticari süzme bal örneği naftalin kalıntısı bakımından incelenmiş ve örneklerin \%9.16'sının (120/11) naftalin kalıntısı yönünden pozitif olduğu saptanmıştır. Pozitif bal örneklerindeki naftalin kalıntı düzeyinin ise 1.1 ile $6.2 \mathrm{ppb}$ arasında olduğu belirlenmiştir. Tosunoğlu (2015) ise Bursa ilinde satışa sunulmuş olan 45 adet bal örneğinde naftalin analizi yapmış ve analiz sonucunda çalışılan hiçbir örnekte tespit limiti olan $2 \mu \mathrm{g} \mathrm{kg}^{-1}$ değerinin üzerinde naftalin kalıntısına rastlamamıştır. Gölge ve ark. (2017) Adana, Osmaniye ve Mersin illerindeki market ve bal üreticilerinden 2015 ve 2016 yıllarında tedarik edilen toplam 90 adet süzme balda naftalin analizleri yapmışlar ve örneklerin sadece bir tanesinde naftalin tespit etmişlerdir. Bu çalışmada da GC-MS cihazı kullanılarak 30 adet süzme bal ve 30 adet petekli bal örneği olmak üzere toplam 60 adet bal örneğinde naftalin kalıntı analizi yapılmıştır. Analiz edilen toplam 60 adet örneğin 3 adedinde Türk Gıda Kodeksi Bal Tebliği'nde naftalin için belirtilen $10 \mu \mathrm{g} \mathrm{kg}^{-1}$ düzeyinin altında $3.0 \mu \mathrm{g} \mathrm{kg}^{-1}, 3.9 \mu \mathrm{g} \mathrm{kg}^{-1}$ ve $8.9 \mu \mathrm{g} \mathrm{kg}^{-1}$ düzeyinde naftalin kalıntısı tespit edilmiştir (Sekil 1). Naftalin konusunda bu çalışmanın ve son yılllarda yapılan araştırmaların sonuçları, geçmiş yıllarda ülkemiz ballarında önemli bir sorun olan naftalin kalıntısı probleminin giderek azaldığını göstermektedir.

\section{Sonuç}

Sınırlı bir bölgede ve örnek sayısında yapılan bu çalışma sonuçlarına bağlı olarak ülke balları ile ilgili genel bir değerlendirmede bulunmak doğru olmayacaktır. Bununla birlikte en az 30 kovana sahip, ticari olarak arıcılık yapan arıcılardan alınan 60 bal örneğinin hiç birinde incelenen pestisit ve antibiyotik bileşenlerinin kalıntısının bulunmaması ve yalnız üç adet örnekte de Türk Gıda Kodeksi Bal Tebliğinde naftalin için belirtilen $10 \mu \mathrm{g} \mathrm{kg}^{-1}$ düzeyinin altında naftalin tespit edilmesi ülkemiz ballarındaki kalıntı sorununun çözümünde arıcıların eğitimi, hızlı kalıntı analiz ve izleme tekniklerinin geliştirilmesi gibi bazı uygulamaların önemli katkı sağladığını göstermektedir. Analiz edilen bal örneklerinde pestisit ve 


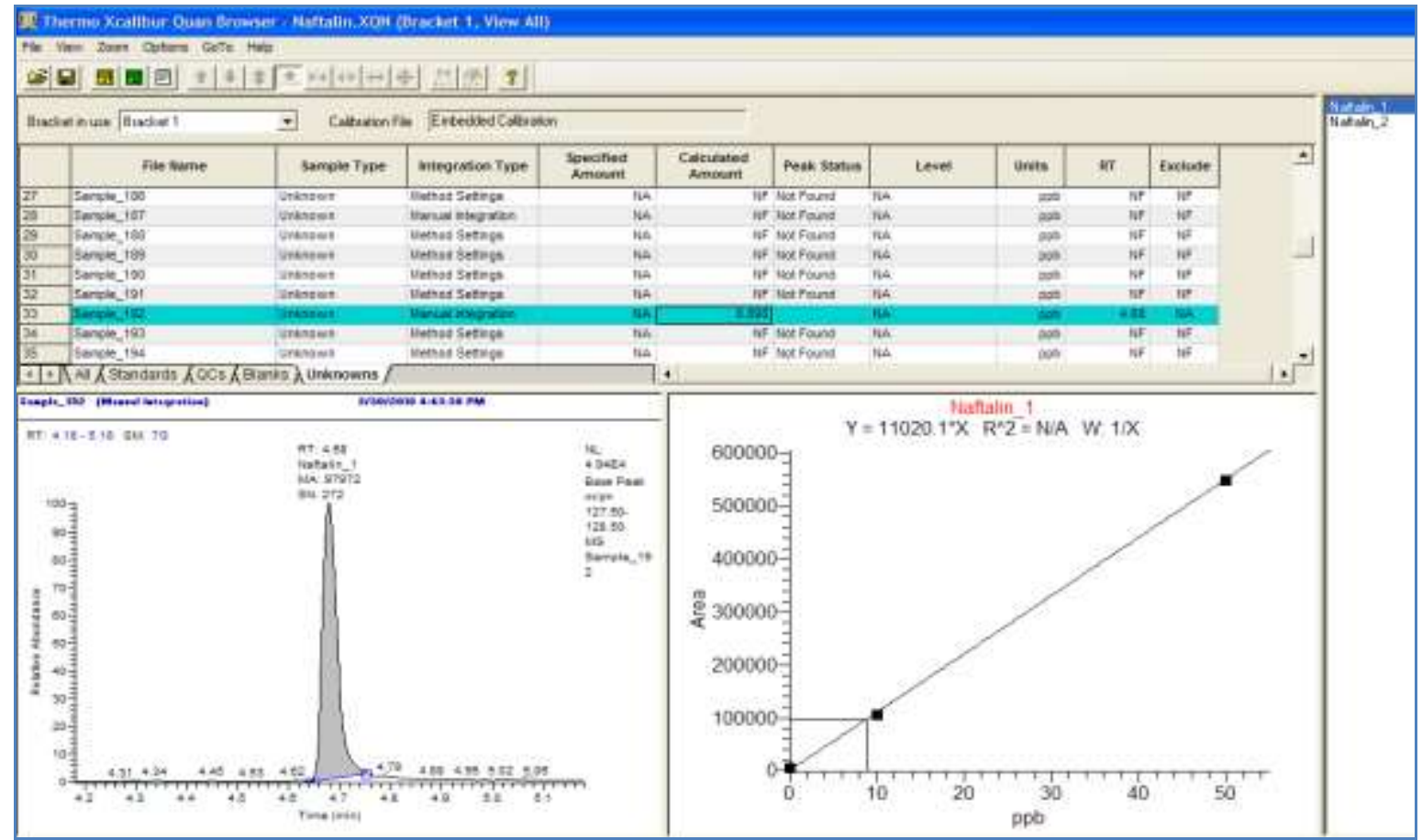

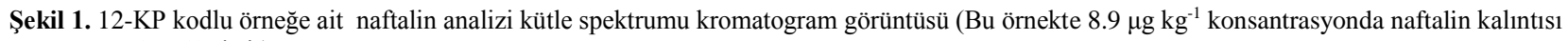
tespit edilmiştir).

Figure 1. Chromatogram obtained by GC-MS for $12 \mathrm{KP}$ honey sample that contains $8.9 \mu \mathrm{gg}^{-1}$ of naphthalene.

antibiyotik bileşenlerinin kalıntısına rastlanmadığı için bu bileşenlerin süzme ve petekli bal örnekleri içerisindeki değişimi tespit edilememiştir. Yalnız üç petekli bal örneğinde Türk Gıda Kodeksi Bal Tebliğinde naftalin için belirtilen $10 \mu \mathrm{g} \mathrm{kg}^{-1}$ düzeyinin altında $3.0 \mu \mathrm{g} \mathrm{kg}^{-1}, 3.9 \mu \mathrm{g} \mathrm{kg}^{-1}$ ve $8.9 \mu \mathrm{g} \mathrm{kg}^{-1}$ düzeyinde naftalin kalıntısı tespit edilmiştir. Naftalin kalıntısı tespit edilen üç çerçeve petekli bal örneklerinden alınarak süzülen bal örneklerinde ise naftalin kalıntısına rastlanmamıştır. $\mathrm{Bu}$ durum, petekli ballaların süzme ballara göre naftalin kalıntısı bakımından daha fazla risk taşıdığını göstermektedir. Bazı ülkelerde hiç olmayan, bazı ülkelerde ise çok az miktarda olan petekli bal tüketimi ülkemizde oldukça yaygındır. Türkiye'nin önemli bir bal mumu ithalatçısı olması, bal arılarının peteği üretmek için fazla işgücü harcamaları ve bal tüketmeleri, bal mumumun değerli bir besin olmaması ve sindirilmeden atılması, ithal edilen veya kontrolsüz ülkeye giren bal mumlarının patojen taşıma riskinin yüksek olması, bal mumundan temel petek üretme sürecinde steril koşulların sağlanmaması ve insan sağlığını tehdit edecek bazı maddelerin katılma riski gibi birçok nedenle süzme balların tercih edilmesi gerekmektedir. Ayrıca bal mumu kimyasalları emen ve depolayan bir yapıdadır. $\mathrm{Bu}$ çalışmanın sonuçları da balmumunun diğer bir ifade ile peteğin naftalin gibi uçucu olan çok zararlı bir bileşiği emdiği ve kalıntı bıraktığını doğrulamaktadır. Tüketiciler petekli balın daha doğal olduğunu düşünürlerken aslında süzme ballara oranla daha fazla riskle karşı karşıya kalmaktadırlar. Bu nedenle ilgili kamu kurumları, arıcılık örgütleri ve bal sektörünün temsilcileri tüketicileri bu konuda doğru bilgilendirmeleri ve petekli bal tüketimi yerine süzme bal tüketimini teşvik etmeleri yararlı olacaktır.

Arı Yetiștiricileri Birlikleri tarafından arıcıların, hastalık ve zararlılarla mücadele konusundaki eğitimlerinin artırılarak sürdürülmesi, arı hastalık ve zararlılarına karşı yapılacak ilaçlamaların bal üretim dönemi dışında, ilkbahar ve sonbahar mevsimlerinde yapılması, özellikle varroa'ya karşı ruhsatlı ilaçların aynı zaman diliminde aynı bölgede toplu olarak yapılmasının sağlanması, peteklerin korunmasına yönelik risk taşımayan ve kolay uygulanan yöntemlerin geliştirilmesi arı ürünlerinde kalıntının önlenmesine önemli katkı sağlayacaktır. Balda kalıntı analizlerinin her yerde yapılamaması ve pahalı olması bireysel olarak arıciların ve tüketicilerin bu analizleri yaptırmasını olanaklı kılmamaktadır. Bu konuda en önemli görev Arı Yetiştiricileri Birlikleri'ne, bal satışı yapan firmalara ve Tarım ve Orman Bakanlığı'na düşmektedir. Marketlerden veya üreticilerden rutin bir şekilde örnekler alınarak kalıntı analizleri yapılmalıdır. Arıcılardan alınan ballar üzerinde gerekli analiz ve denetimleri yaparak tüketime sunulmalıdır. Tarım ve Orman Bakanlığı, balda tağşiş yapan ve Türk Gıda Kodeksi Bal Tebliğine uygun olmayan bal örneklerinin ait olduğu firmaları kamuoyuna açıklamaktadır. Benzer şekilde marketlerden veya üreticilerden alınan bal örneklerinde kalıntı analizleri de yapılarak ballarında kalıntı içeren firmalar açıklanmalıdır. Sonuç olarak hem halk sağlığı ve gıda güvenliği hem de arıcılık sektörünün geleceği için; arı ürünlerinin üretiminden tüketimine kadar geçen süreçteki tüm faaliyetlerin sektör içindeki her kesimin kabul edeceği ilke ve kurallara uygun olarak sürdürülmesi, arı ürünlerinde kalıntının önlenmesi konusunda üretici, tüketici ve satıcıların bilinçlendirilmesi, etkin ve yaygın denetimin sağlanması gerekmektedir.

\section{Teșekkür}

Bu çalışma "Süzme ve petekli balların pestisit, naftalin ve antibiyotik kalıntıları bakımından karşılaştırılması" başlıklı Yüksek Lisans Tezi’nden özetlenmiştir ve Akdeniz Üniversitesi Bilimsel Araştırma Projeleri Koordinasyon Birimi tarafından FYL-2710 nolu proje ile desteklenmiştir. 


\section{Kaynaklar}

Açar ÖÇ (2015) Pestisit analizleri eğitim notu. Gıda Tarım ve Hayvancılık Bakanlığı, Ulusal Gıda Referans Laboratuarı, Ankara

Anonim (2012) Türk Gıda Kodeksi Bal Tebliği, Tebliğ No: 2012/58, Gıda Tarım ve Hayvancılık Bakanlığı, Resmi Gazete, 27.07.2012 ve 28366 say1.

Anonim (2018) Gıda, Tarım ve Hayvancılık Bakanlı̆̆ı, Hayvanc1lık Genel Müdürlüğü, https://www.tarimorman.gov.tr/sgb/Belgeler/SagMenuVeril er/HAYGEM.pdf. Erişim 24 Aralık 2018.

Beyoğlu D, Omurtag GZ (2007) Occurrence of naphthalene in honey consumed in Turkey as determined by high pressure liquid chromatography. Journal of Food Protection 7: 7-15.

Derebaşı E, Bulut G, Col M, Güney F, Yaşar N, Ertürk Ö (2014) Physicochemical and residue analysis of honey from black region of Turkey. Fresenius Environmental Bulletin 23(1): 10-17.

Gölge Ö, Hepsağ F, K1lınççeker O (2017) Determination of naphthalene levels of honey in eastern mediterranean region. ADYÜTAYAM 5(2):14-23.

Gül A (2008) Türkiye'de üretilen bazı balların yapısal özelliklerinin gıda güvenliği bakımından araştırılması. Doktora Tezi, Mustafa Kemal Üniversitesi Fen Bilimleri Enstitüsü, Hatay.

Gürel F (2012) Arıcılık sektörü ve etik ilkeler. TSE Standart Ekonomik ve Teknik Dergi 601: 74-79.

Gürel F (2015) Balda taklit ve tağşiş. Arıcılık Araştırma Enstitüsü Arıcılık Araştırma Dergisi 7(13): 2-4.

Karacaoğlu M, Uçak Koç A, Çerçi A (2012) Assessment of naphthalene residues in beeswax foundations stored in windscreen cabinets. Asian Journal of Animal Science 6(1): 42-46.

Lehotay S, Neil MO, Tully J, Valverde A, Contreras M, Mol, et al. (2007) Determination of pesticide residues in foods by acetonitrile extraction and partitioning with magnesium sulfate: Collaborative study. Journal of AOAC International 90(2): 485-520.

Saygılı M (2017) Kirklareli ilinde arıcılık faaliyeti yapan üreticilerden toplanan peteklerde antibiyotik ve pestisit kalıntısı aranması. Yüksek Lisans Tezi, Namık Kemal Üniversitesi, Tekirdağ.

Selçukoğlu E (1999) Çukurova Bölgesi'nde toplanan bal örneklerinden amitraz ve fulvalinate kalıntılarının belirlenmesi. Doktora Tezi, Ankara Üniversitesi, Ankara.

Şireli T (2013) Süzme ballarda GC-MS metodu ile naftalin kalıntısının incelenmesi. Ankara Üniversitesi Bilimsel Araştırmalar Projesi Sonuç Raporu, BAP No: 12H3338002, Ankara.

Tosunoğlu H (2015) Bursa ilinde satışa sunulmuş balların naftalin kalıntısı yönünden incelenmesi. Uludağ Arıcılık Dergisi 15(2): 41-46.

Tutkun E, İnci A (1992) Bal arısı zararlıları hastalıkları ve tedavi yöntemleri. Demircioğlu Matbaacılık, Ankara.

Uludağ R (2008) Ege bölgesinde tüketime sunulan ballarda sülfonamid kalıntılarının araştırılması. Yüksek Lisans Tezi, Adnan Menderes Üniversitesi, Aydın.

Zai IUM, Rehman K, Hussain A (2013) Detection and quantification of antibiotics residues in honey samples by chromatographic techniques. Middle-East Journal of Scientific Research 14(5): 683-687. 